\title{
Finite element modelling of thin intermetallic compound layer fractures
}

\section{Ooi Eang Pang*, Ruslizam Daud, Nasrul Amri Mohd Amin, Mohd Afendi Rojan and Mohd Shukry Abd Majid}

Fracture and Damage Mechanic SIG, School of Mechatronic Engineering, University Malaysia Perlis 02600, Arau, Perlis, Malaysia

*Email: eangpang@yahoo.com.my

*Phone: +60125763336;

\begin{abstract}
A thin intermetallic compound (IMC) of solder ball joint induces strong stress concentration between the pad and solder where a crack propagated near the IMC layer. The fracture mechanism of the IMC layer is complex due to the effect of IMC thickness, crack length, solder thickness and Young's Modulus. At present, there is still an undefined exact geometrical model correlation for numerical simulations of IMC layer fracture. Thus, this paper aims to determine the accuracy of IMC layer models subjected to crack-to-width length ratio (a/W) in correlation with the ASTM E399-83 Srawley compact specimen model using finite element (FE) analysis. Several FE models with different geometrical configurations have been proposed under $10 \mathrm{MPa}$ tensile loading. In this study, the two dimensional linear elastic displacement extrapolation method (DEM) is formulated to calculate the stress intensity factor (SIF) at the crack tip. The study showed that with an error of $0.58 \%$ to $0.59 \%$, a width of $2.1 \mathrm{~mm}$ and a height of $1.47 \mathrm{~mm}$ can be recommended as the best geometrical model for IMC layer fracture modelling which provides a wider range for a/W from 0.45 to 0.85 instead of from 0.45 to 0.55. This result is significant as it presents a method for determining fracture parameters at thin IMC layers with a combination of singular elements with meshes at different densities which is tailored to the Srawley model.
\end{abstract}

Keywords: Intermetallic compound; solder ball joint; stress intensity factor; finite element analysis.

\section{INTRODUCTION}

The prevalence of failure in solder joints is due to thermo-mechanical stress that fails by brittle fracture near the solder-intermetallic compound interface (IMC). Previously, IMCs were concentrated at the interface between the pad and the solder material [1-5]. The brittle property of IMCs was reported to cause a strong stress concentration effect during mechanical impacts [6-10]. In remark, the presence of IMC has greatly influenced the reliability of solder joints. Alam et al. [11] showed that mixed mode stress intensity factors (SIF) (e.g. $K_{I}$ and $K_{I I}$ ) increase with the thickness of solder alloys at a loading rate of $0.8 \mathrm{MPa} / \mathrm{s}$ for a crack located at the middle of the IMC layer. The study also highlighted that near to the crack location, for higher values of $K_{I}$ and $K_{I I}[3,11,12]$, thinner IMC layers have a stronger effect on the SIF which lead to unstable cracks. In order to investigate the characteristics of solder joints using finite element methods, the fracture 
parameter $\mathrm{K}_{\mathrm{I}}$ calculated from $\mathrm{FE}$ modelling has to be validated with standard test data. The ASTM standard test for compact specimen, E399-83, introduced by Srawley in 1976 $[13,14]$ is commonly employed. However, the appropriate geometry of the model width and height reference is still a topic of discussion [15-17]. Therefore, this paper aims to verify and evaluate the best geometrical parameter of the solder joints FE model, which is validated using the Srawley analytical equation for accurate IMC fracture behaviour assessment.

\section{MATERIALS AND METHODS}

\section{Finite Element Modelling}

The modelling of the IMC layer brittle fracture mechanism required the confirmation of appropriate analytical models of metallic fracture to agree with the theoretical model. This study involved numerical simulations mainly to identify the most accurate width $W$ for solder ball joint fracture analysis. The effect of crack length $a$, solder thickness $H$, IMC layer thickness $h$ and Young's Modulus $E$ on the fracture behaviour of the solder joint are investigated using the linear elastic fracture mechanics (LEFM) approach. By taking the ASTM E399-83 Srawley model as a reference [13, 14], numerical FE modelling is conducted using FE software ANSYS APDL to determine the Mode I stress intensity factor (SIF) $K_{I}$ of a single edge crack. SIF for the ASTM E399-83 Srawley model are written as follows.

$$
\begin{gathered}
K_{I s}=Y_{s} \sigma_{a} / B W^{0.5} \\
Y_{s}=\frac{\left(2+\frac{a}{W}\right)}{\left(1-\frac{a}{W}\right)^{3 / 2}}\left[0.866+4.64\left(\frac{a}{W}\right)-13.36\left(\frac{a}{W}\right)^{2}+14.72\left(\frac{a}{W}\right)^{3}-5.6\left(\frac{a}{W}\right)^{4}\right]
\end{gathered}
$$

where $K_{I s}$ is SIF for the Srawley model, $Y_{s}$ is the shape function, $\sigma_{a}$ is applied loading, $B$ is the thickness taken as $1.0 \mathrm{~mm}, a$ is the crack length, and $W$ is the width of solder. Table 1 shows the material properties of the material model.

Table 1. Optimum dimension obtained from modelling process.

\begin{tabular}{lc}
\hline \multicolumn{1}{c}{ Material } & Intermetallic compound (IMC) \\
\hline Height/thickness $(\mathrm{mm})$ & 1.47 \\
Width $(\mathrm{mm})$ & 2.1 \\
Crack length $(\mathrm{mm})$ & 1.05 to 1.68 \\
\hline
\end{tabular}

The FE specimen is schematized by a 2D model in which the specimen thickness was kept at $1.0 \mathrm{~mm}$. The FE model is set to different $W$ values $(1,2,3$ and $5 \mathrm{~mm})$ while the model analysis was conducted in plain strain condition. The meshing scheme was set to isoperimetric quadrilateral elements (PLANE 183) with a Barsoum singularity element around the crack tip since this increases the accuracy of the measurement [17-20]. To confirm the accuracy, a convergence study was conducted [21-23]. The meshing scheme model is shown in Figure 1. The best meshing size for the radius of the $1^{\text {st }}$ row of elements about the key point 2 is $1 / 30$ compared to $1 / 10$ and $1 / 20$. The error for the $1^{\text {st }}$ row radius size $1 / 30$ is the smallest validated by the Srawley equation (2). The global size element edge is fixed at $1 / 30$ and the element size around the crack tip controlled at $1 / 30$. For local meshing, $1 / 20$ is selected as a suitable meshing value since the error is between $0.58 \%$ to $0.60 \%$. The modelling was confirmed with a full FE model for solder joint model, as 
shown in Figure 2. Table 2 shows the material properties for the full FE model solder joint modelling.

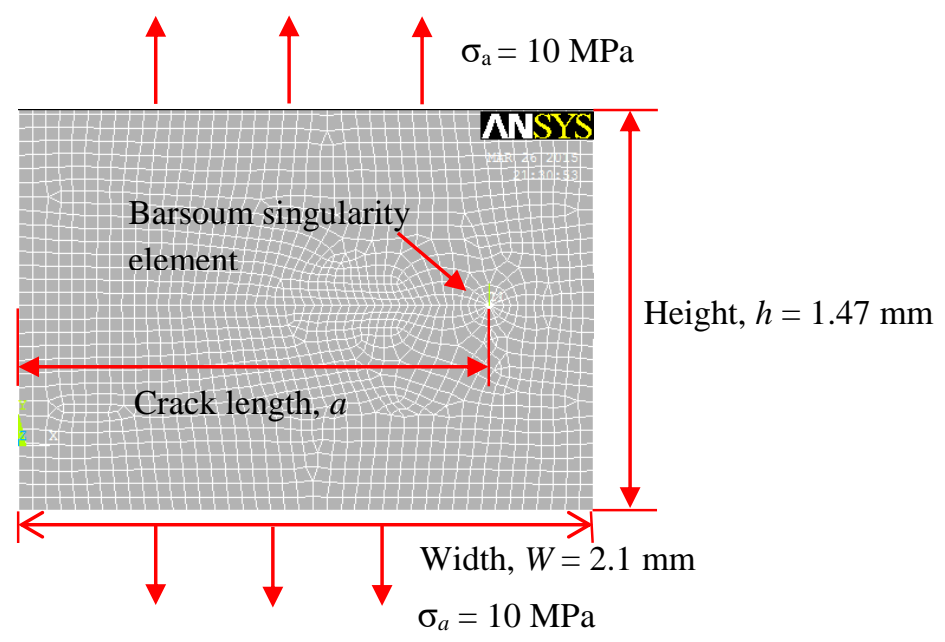

Figure 1 Meshing scheme for the ASTM E399-83 Srawley Model.

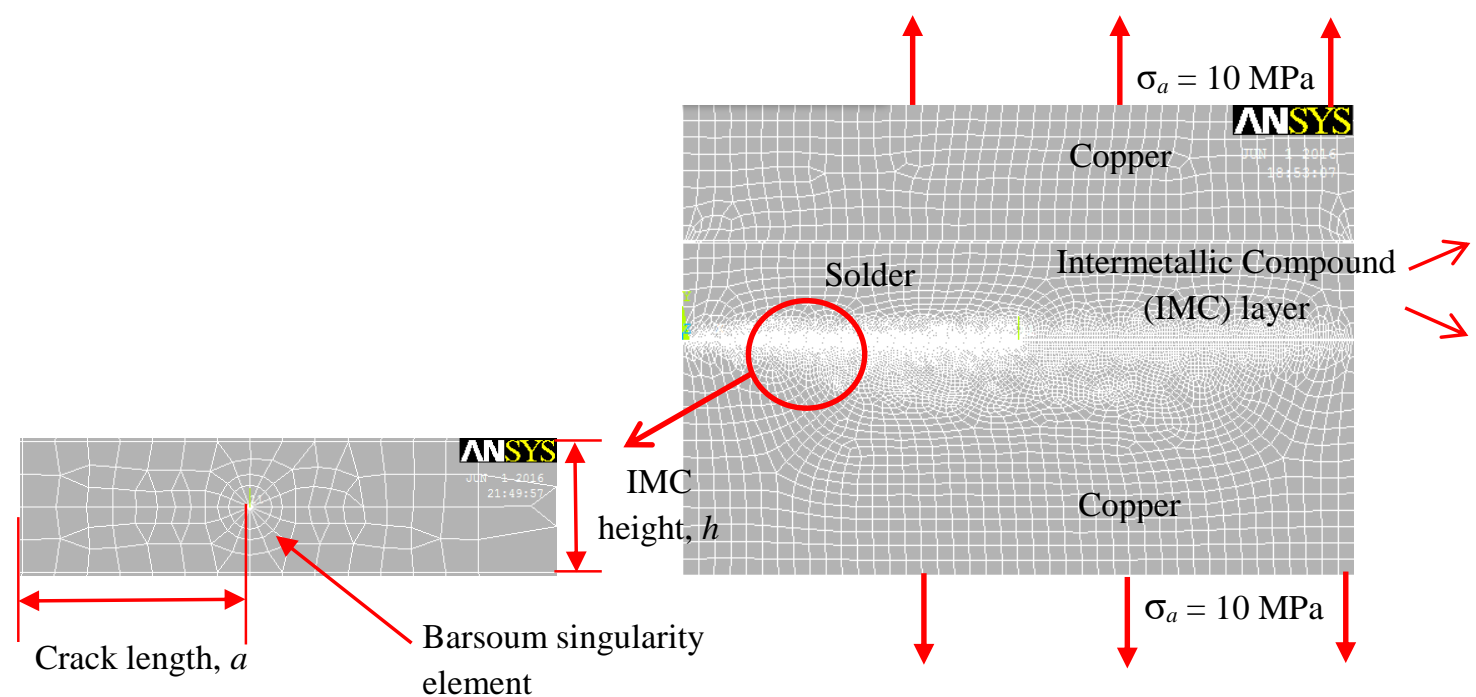

Figure 2. Full FE model for the solder joint model.

Table 2. Material properties for solder joint modelling [24].

\begin{tabular}{lcc}
\hline Materials & $\begin{array}{c}\text { Elastic modulus, E } \\
(\mathrm{GPa})\end{array}$ & Poisson ratio, $v$ \\
\hline Intermetallic compound (IMC) & 110 & 0.30 \\
Lead-free solder SnAgCu (SAC) & 43 & 0.30 \\
Leaded solder Sn37Pb Eutectic (SnPb) & 35 & 0.36 \\
Copper $(\mathrm{Cu})$ & 129 & 0.34 \\
\hline
\end{tabular}

In this study, the Mode I stress intensity factor (SIF) is calculated by using the displacement extrapolation method (DEM) and is expressed as follows [25]: 


$$
K_{I}=\frac{E}{3(1+v)(1+K)} \sqrt{\frac{2 \pi}{L}}\left(4\left(v_{2}-v_{4}\right)-\frac{v_{3}-v_{5}}{2}\right)
$$

where $E$ is Young's Modulus, $K=\frac{3-4 v}{1-v}$ for plane strain, $L$ is the length of the element and $v$ is the displacement in the local Cartesian coordination system.

\section{RESULTS AND DISCUSSION}

\section{IMC Width Identification vs Srawley}

Figure 3 shows the normalised SIF $Y_{F E}$ at various $a / W$ crack-widths. In this first stage of the simulation, the larger the geometry model width, the larger the $Y_{F E}$ factor of the model from the $Y_{s}$ theoretical value. A width of $4.0 \mathrm{~mm}$ only matches the Srawley analytical model at a/W from 0.1 to 0.2 and starts to deviate further starting from 0.3 onwards. The $3 \mathrm{~mm}$ width data graph is only close to the Srawley analytical model at an a/W of 0.4 , while the rest show a lot of difference. As for widths of $1.0 \mathrm{~mm}$ and $2.0 \mathrm{~mm}$, the model is matched to the analytical model for a/W from 0.4 to 0.6 . The FE model with a $1.0 \mathrm{~mm}$ width becomes much lower than the analytical data starting from 0.6 onwards. Based on Figure 3, it was identified that the FE model with a $2 \mathrm{~mm}$ width has the nearest $Y_{F E}$ factor to the $\mathrm{Y}_{S}$ Srawley mathematical equation for an $a / W$ from 0.4 to 0.90 , with a $\%$ error of $0.43 \%$ to $-3.86 \%$.

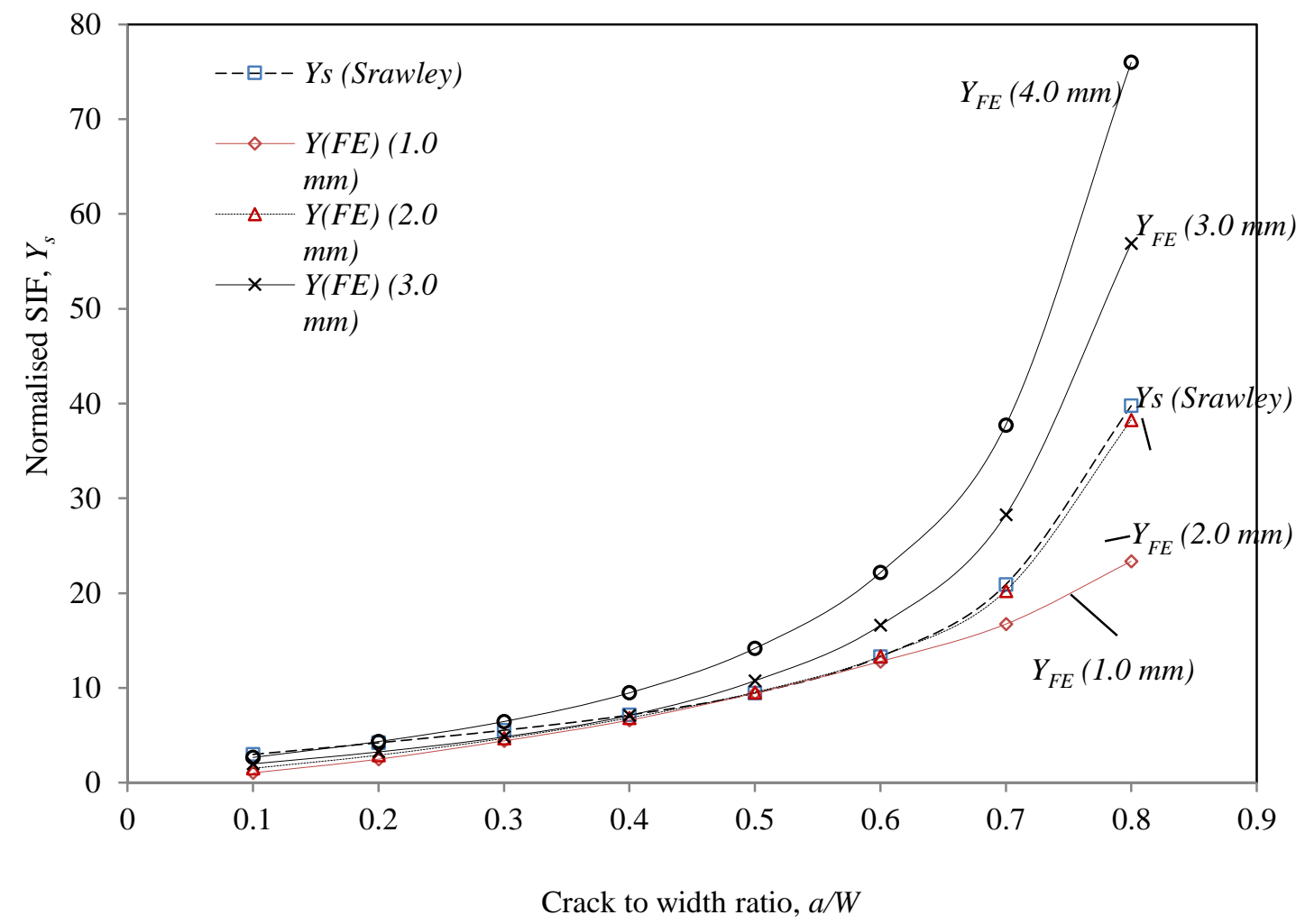

Figure 3 Normalised SIF, $Y_{s}$ of difference width 1.0, 2.0, 3.0 and $4.0 \mathrm{~mm}$ against crackto-width ratio for first width determination.

To find a more accurate model, the width dimension around $2 \mathrm{~mm}$ is chosen in the $2^{\text {nd }}$ stage width determination. Figure 4 shows the $2^{\text {nd }}$ stage FE model width results 
for $1.5 \mathrm{~mm}, 1.8 \mathrm{~mm}, 2.0 \mathrm{~mm}$ and $2.2 \mathrm{~mm}$ compared to the Srawley equation. The model with widths of $1.5,1.8$ and $2.0 \mathrm{~mm}$ results in graphs that gradually approach the analytical model from $1.5 \mathrm{~mm}$ to $2.0 \mathrm{~mm}$. However, a width of $2.2 \mathrm{~mm}$ shows a reading higher than the analytical model starting with an a/W of 0.6 . Figure 4 indicates that the right model width should be between $2.0 \mathrm{~mm}$ and $2.2 \mathrm{~mm}$, which is closer to the Srawley equation value. In this case, the width has been redefined to obtain a more accurate width dimension in the $3^{\text {rd }}$ stage width determination. Figure 5 shows the $3^{\text {rd }}$ stage of refined for a width of $2.0 \mathrm{~mm}$ to $2.2 \mathrm{~mm}$. It was confirmed that the best width of the numerical model should be $2.1 \mathrm{~mm}$ which is almost similar to the Srawley analytical equation for a crackto-width range of 0.5 to 0.8 and a $Y_{F E} \%$ error of less than $0.6 \%$.

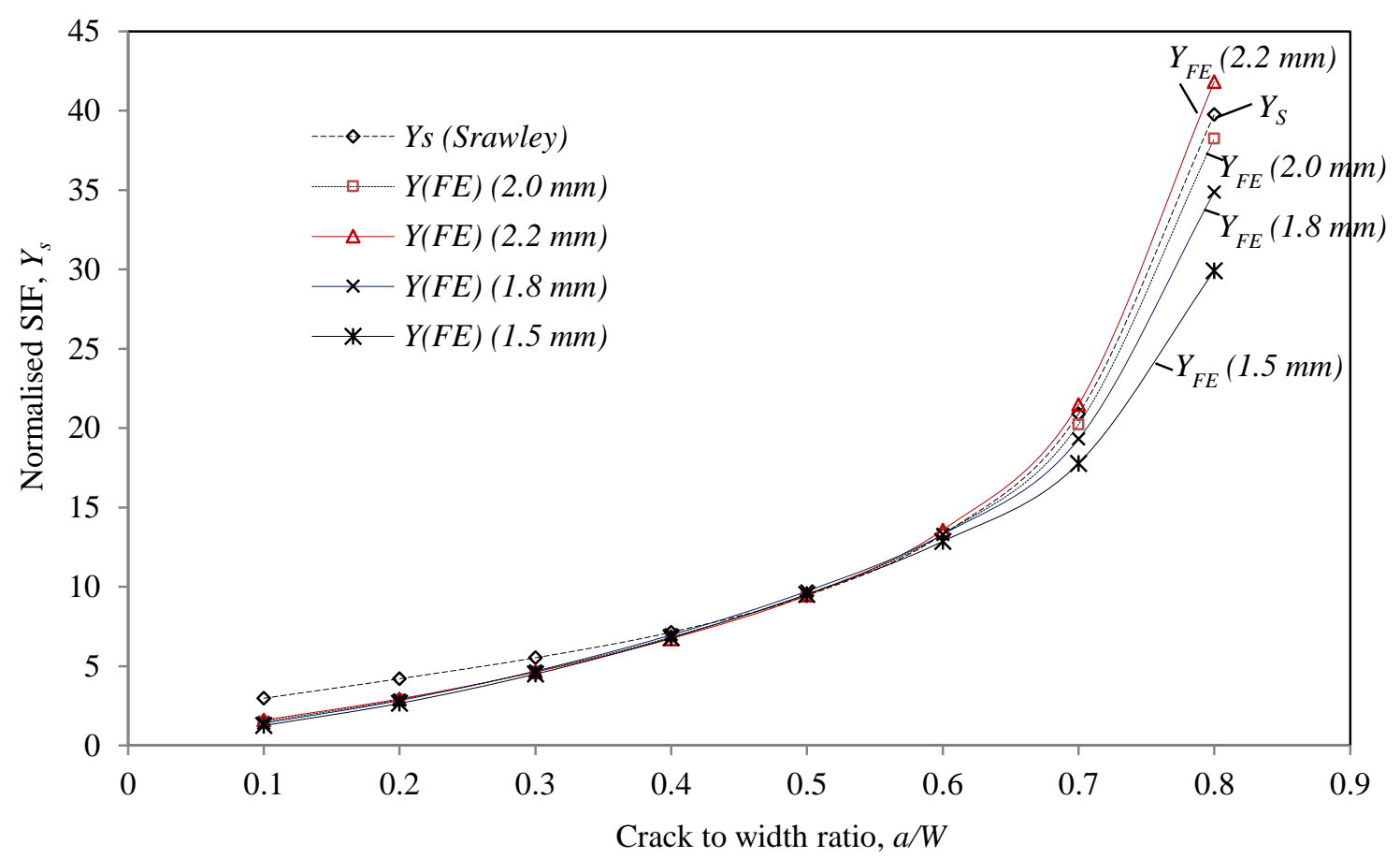

Figure 4. Normalised SIF, $Y_{s}$ of difference width 1.5, 1.8, 2.0 and $2.2 \mathrm{~mm}$ versus crackto-width ratio in the $2^{\text {nd }}$ stage of width determination.

Figure 4 and 5 also indicate that model widths of 1.8, 2.0, 2.1 and $2.2 \mathrm{~mm}$ are matched with the analytical model for an a/W range from 0.4 to 0.6 , while a width of 1.5 $\mathrm{mm}$ has a slightly bigger deviation at an a/W of 0.6. Overall, a model width from $1.8 \mathrm{~mm}$ to $2.2 \mathrm{~mm}$ can be accepted to be the model width for an a/W range from 0.4 to 0.6 , which agrees with the study by Anderson [26]. Figure 6 shows the height determination process using heights of $1.3,1.4,1.47,1.50,1.60$ and $1.70 \mathrm{~mm}$ and indicates that the $\%$ error for geometry height $(1.3 \mathrm{~mm}$ to $1.7 \mathrm{~mm})$ is within $-8.84 \%$ to $0.28 \%$ for an $a / W$ of 0.5 to 0.8 . This dimension is far from the target value but is offset on the negative side. The graphs of height $1.47 \mathrm{~mm}$ and $1.50 \mathrm{~mm}$ are very close to the $Y_{s}$ of the Srawley model. Hence, a $2^{\text {nd }}$ height determination $(1.45 \mathrm{~mm}$ to $1.49 \mathrm{~mm})$ is carried out to find out the best magnitude for the FE model height. 


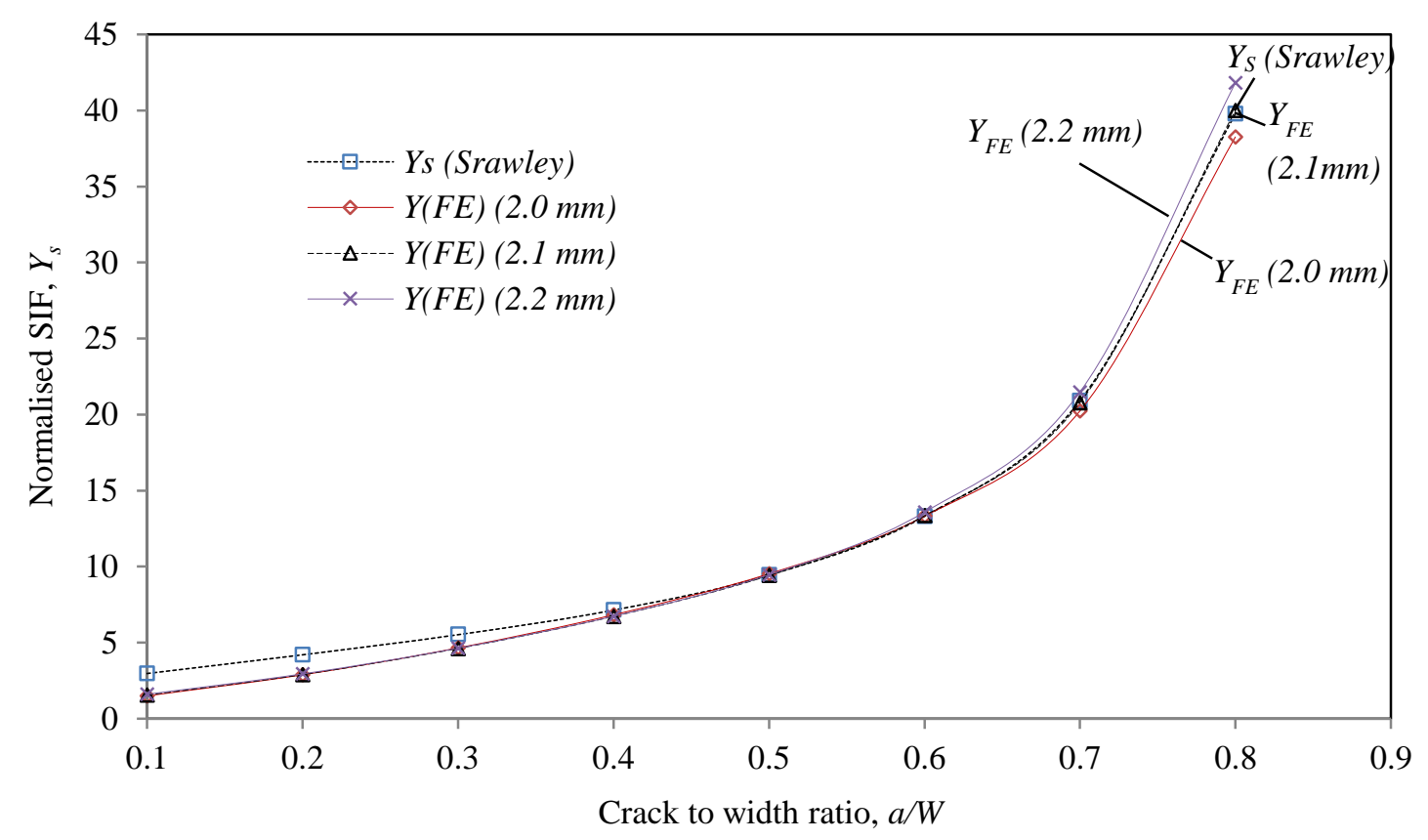

Figure 5. Normalised SIF, $Y_{F E}$ of 2.0, 2.1 and $2.2 \mathrm{~mm}$ width against crack-to-width ratio in the $3^{\text {rd }}$ width refinement.

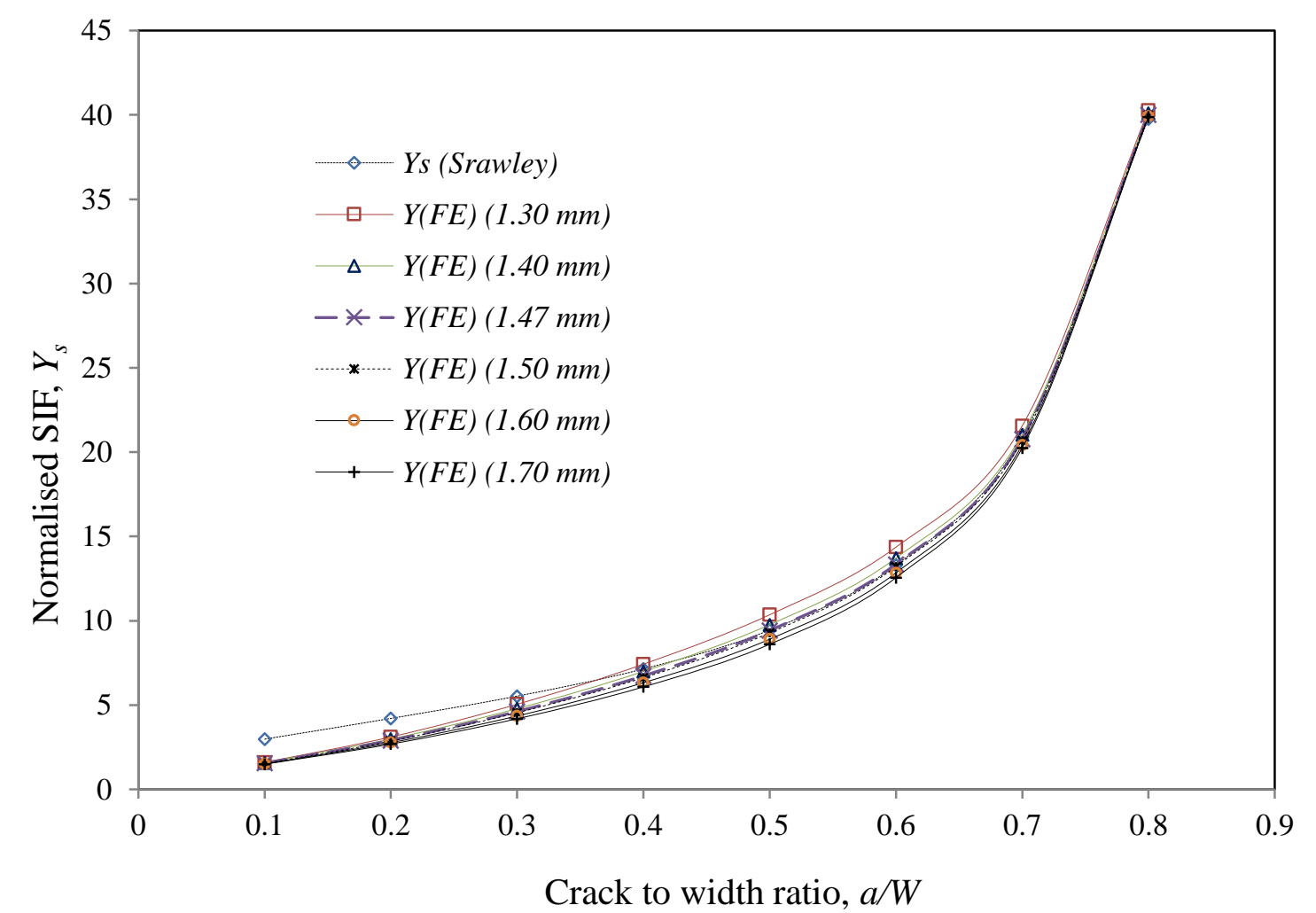

Figure 6 data showing the $\%$ error for geometry height $(1.3 \mathrm{~mm}$ to $1.7 \mathrm{~mm})$.

Figure 7 is plotted to determine the 2nd height determination process and shows that the ideal height for the $2.1 \mathrm{~mm}$ width model is $1.47 \mathrm{~mm}$ with the smallest $Y_{s} \%$ error $(0.60 \%)$ when validated with the Srawley analytical equation for an $a / W$ range of 0.5 to 
0.8. Heights of $1.45,1.46,1.48$, and $1.49 \mathrm{~mm}$ show $Y_{s} \%$ errors of $1.10 \%, 0.73 \%,-0.80 \%$ and $-1.26 \%$, respectively. Hence, the simulation results show that the model height that can be used is from 1.45 to $1.50 \mathrm{~mm}$. For the greatest accuracy, it is recommended to use $h=1.47 \mathrm{~mm}$ as the geometry height for the FE model.

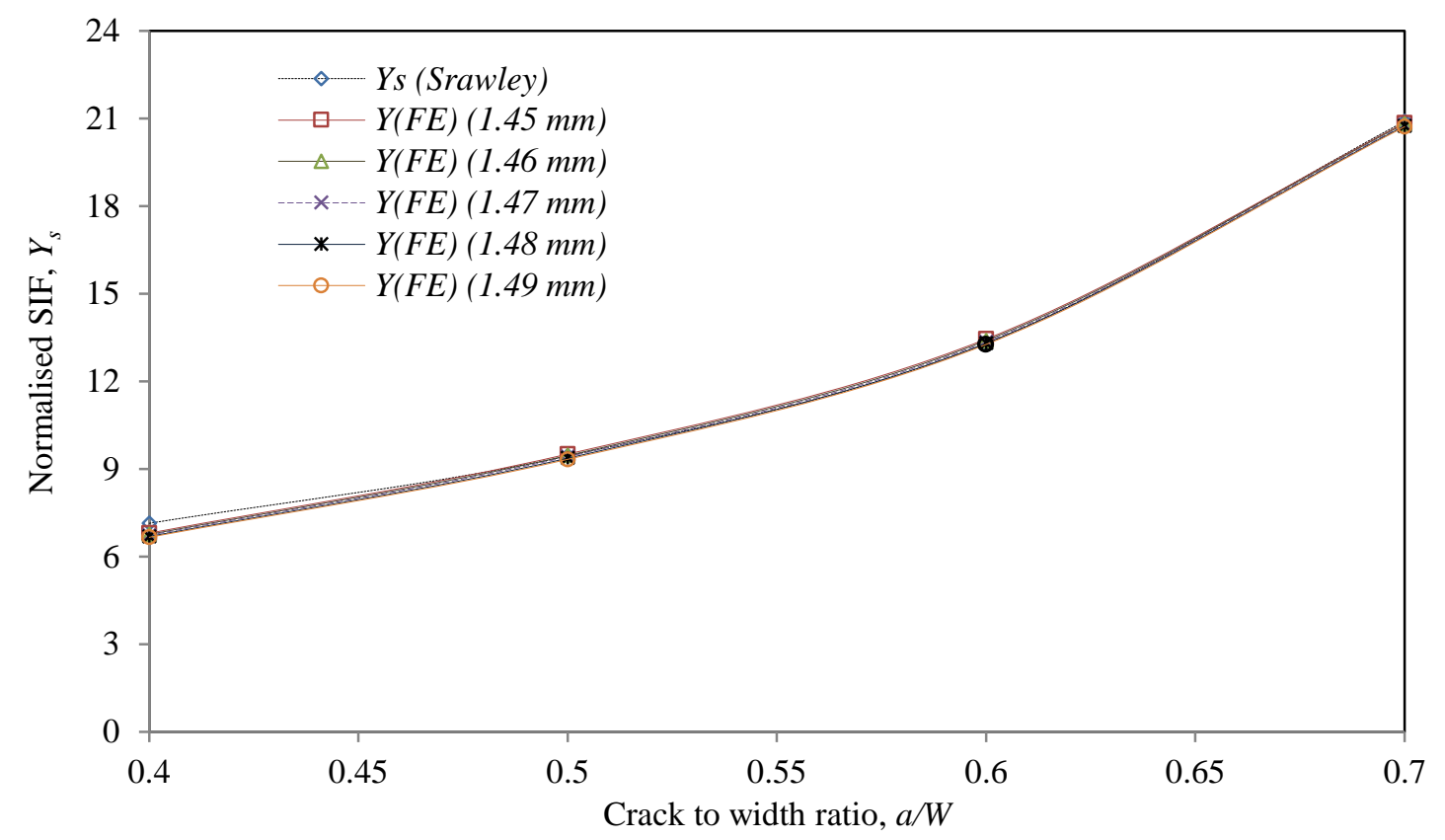

Figure 7. Normalised SIF, $Y_{s}$ of 1.45 to $1.49 \mathrm{~mm}$, height of $2.1 \mathrm{~mm}$ width FE models versus crack-to-width ratio.

\section{Singularity Element Geometry}

As the best geometry FE model has been identified, the next important step is the meshing of the model need to be refined in order to obtain a more accurate numerical model to mimic the Srawley analytical equation. The best width and height of the model geometry used are $2.1 \mathrm{~mm}$ and $1.47 \mathrm{~mm}$ respectively. Figure 8 shows the trend of $Y_{s}$ against its crack-to-width ratio for the meshing scheme study. From the graphs in Figure 8, it is clear that the meshing does not show much deviation in terms of $Y_{s} \%$ error but is more accurate with finer meshing, although the improvement is very small. For example, for $1 / 20$ meshing, the \% error is between $0.58 \%$ and $0.60 \%$ and for $1 / 30$ meshing, it improves from $-0.57 \%$ to $0.52 \%$. Smaller meshing will provide better results but too small a meshing size will result in longer computation times and only produce very small improvement in $Y_{s} \%$ error. Therefore, the best meshing size is chosen which can provide accurate results and not cause too much time delays in the computation of the data. As a result, 1/20 is selected as the best meshing size and applied in the full model of the IMC solder joint test. When full FE modelling for a solder joint was carried out as shown in Figure 2 using a smart meshing with size 1, it was verified that different meshing at different material layers give almost the same results when all the solder, IMC and copper layer material has changed into only one IMC material [27]. This gives only a $0.59 \%$ error when compared to the previous model $(0.60 \%)$ discussed in this simulation. 


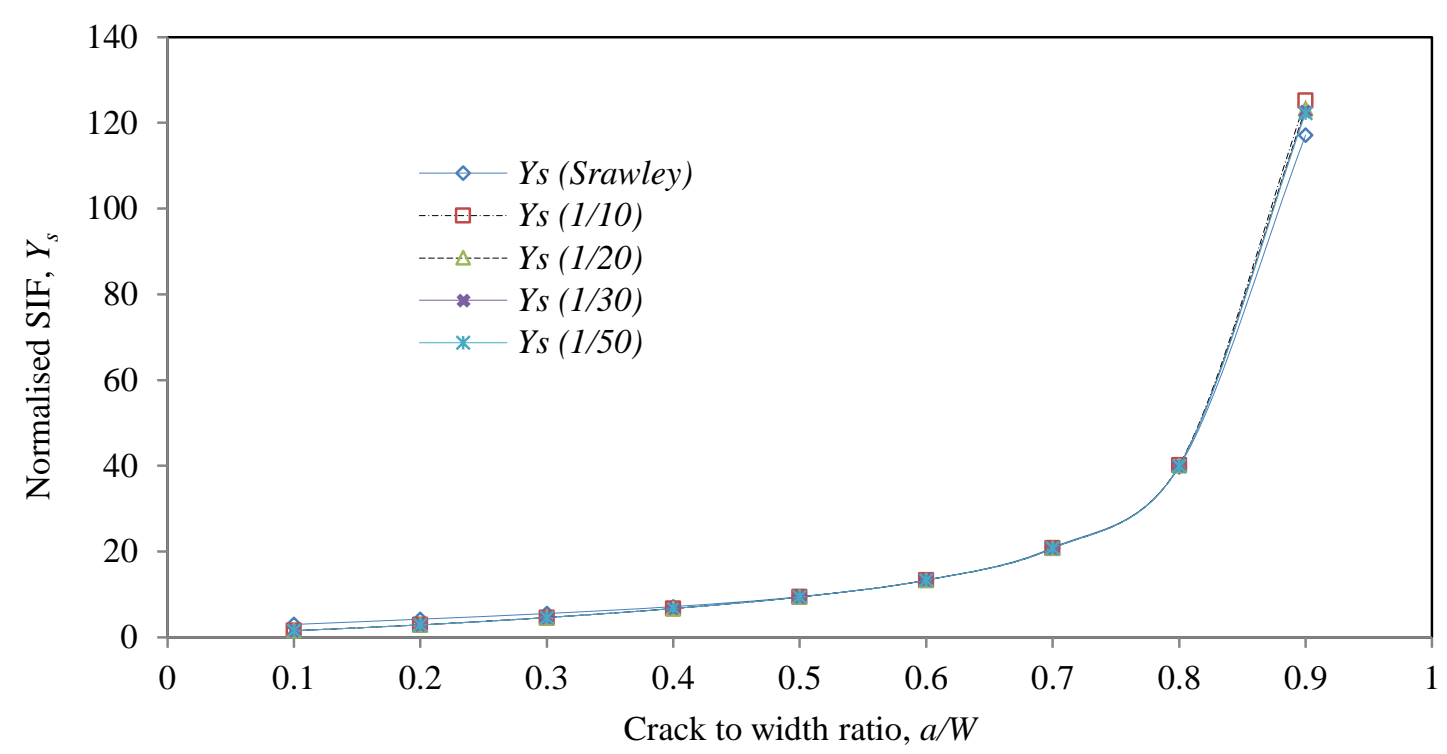

Figure 8. Normalised SIF $Y_{s}$ against crack-to-width ratio for meshing scheme refinement.

\section{CONCLUSIONS}

As stated in the ASTM E399-83 standard test specification, the range of $a / W$ is very stringent and only valid between 0.45 and 0.55 for compact specimens. From this verification study, the analytical equation is best for $\mathrm{a} / \mathrm{W}$ for the range of 0.4 to $0.6 \mathrm{~mm}$ and model width from 1.8 to $2.2 \mathrm{~mm}$. This FE simulation reveals that the Srawley analytical equation can also be used for a wider range of $a / W$ from 0.45 to 0.85 if the width is $2.1 \mathrm{~mm}$ and height is $1.47 \mathrm{~mm}$. Besides, the geometry width $W$ and height $h$ determination for the IMC model as well as the best meshing is finalized at $W=2.1 \mathrm{~mm}$ and $1.4 \mathrm{~mm} \leq h \leq 1.785 \mathrm{~mm}$. This correlates well with the Srawley model. As a conclusion, this result is significant as it presents a method for the determination of fracture parameters at thin IMC layers with a combination of singular elements with meshes at different densities which are tailored to the Srawley model. Further simulations can be based on the new set of IMC widths and heights.

\section{ACKNOWLEDGEMENTS}

The authors would like to be obliged to Fundamental Research Grant Scheme FRGS 9003-00377 and MyPhD from Ministry of High Education (MOHE) of Malaysia for providing Research Fund of Doctoral Program.

\section{REFERENCES}

[1] Tian Y, Hang C, Wang C, Yang S, Lin P. Effects of bump size on deformation and fracture behavior of sn3. 0ag0. 5cu/cu solder joints during shear testing. Materials Science and Engineering: A. 2011;529:468-78.

[2] Le V-N, Benabou L, Tao Q-B, Etgens V. Modeling of intergranular thermal fatigue cracking of a lead-free solder joint in a power electronic module. International Journal of Solids and Structures. 2017;106:1-12. 
[3] Yao Y, Keer LM, Fine ME. Modeling the failure of intermetallic/solder interfaces. Intermetallics. 2010;18:1603-11.

[4] Azmah Hanim MA, Ourdjini A, Saliza Azlina O, Siti Rabiatul Aisha I. Intermetallic evolution for isothermal aging up to 2000 hours on sn-4ag-0.5cu and sn-37pb solders with ni/au layers. International Journal of Automotive and Mechanical Engineering. 2013;8:1348-56.

[5] Azmah Hanim MA, Ourdjini A, Siti Rabiatull Aisha I, Saliza Azlina O. Thermal cyclic test for sn-4ag- $0.5 \mathrm{cu}$ solders on high $\mathrm{p}$ ni/au and ni/pd/au surface finishes. Journal of Mechanical Engineering and Sciences. 2015;9:1571-9.

[6] Nadimpalli SP, Spelt JK. Effect of geometry on the fracture behavior of lead-free solder joints. Engineering Fracture Mechanics. 2011;78:1169-81.

[7] Shen YL, Aluru K. Numerical study of ductile failure morphology in solder joints under fast loading conditions. Microelectronics Reliability. 2010;50:2059-70.

[8] Aluru K, Wen FL, Shen YL. Direct simulation of fatigue failure in solder joints during cyclic shear. Materials \& Design. 2011;32:1940-7.

[9] Lee JH, Jeong HY. Fatigue life prediction of solder joints with consideration of frequency, temperature and cracking energy density. International Journal of Fatigue. 2014;61:264-70.

[10] Nadimpalli SP, Spelt JK. Mixed-mode fracture load prediction in lead-free solder joints. Engineering Fracture Mechanics. 2011;78:317-33.

[11] Alam M, Lu H, Bailey C, Chan YC. Fracture mechanics analysis of solder joint intermetallic compounds in shear test. Computational Materials Science. 2009;45:576-83.

[12] Amalu EH, Ekere NN. High temperature reliability of lead-free solder joints in a flip chip assembly. Journal of Materials Processing Technology. 2012;212:47183.

[13] ASTM-E399-83. Standard test method for plane strain fracture toughness testing of metallic materials. . ASTM Annual Book of Standards, Section 2. 1992;3:1-31.

[14] Srawley JE. Wide range stress intensity factor expressions for astm e 399 standard fracture toughness specimens. International journal of fracture. 1976;12:475-6.

[15] Vashishth D, Behiri JC, Bonfield W. Crack growth resistance in cortical bone: Concept of microcrack toughening. Journal of Biomechanics. 1997;30:763-9.

[16] Zhu W, Smith D. On the use of displacement extrapolation to obtain crack tip singular stresses and stress intensity factors. Engineering Fracture Mechanics. 1995;51:391-400.

[17] Tracey DM. Finite elements for determination of crack tip elastic stress intensity factors. Engineering Fracture Mechanics. 1971;3:255-65.

[18] Mohamed MA, Manurung YHP, Ghazali FA, Karim AA. Finite element-based fatigue life prediction of a load-carrying cruciform joint. Journal of Mechanical Engineering and Sciences. 2015;8:1414-25.

[19] Zulkifli A, Ariffin AK, Rahman MM. Probabilistic finite element analysis on vertebra lumbar spine under hyperextension loading. International Journal of Automotive and Mechanical Engineering. 2011;3:256-64.

[20] Zhu WX, Smith DJ. On the use of displacement extrapolation to obtain crack tip singular stresses and stress intensity factors. Engineering Fracture Mechanics. 1995;51:391-400.

[21] Chan SK, Tuba IS, Wilson WK. On the finite element method in linear fracture mechanics. Engineering Fracture Mechanics. 1970;2:1-17. 
[22] Sinclair GB, Meda G, Smallwood BS. On crack-tip stresses as crack-tip radii decrease. Journal of Applied Mechanics. 2011;78:011004.

[23] Gu GX, Dimas L, Qin Z, Buehler MJ. Optimization of composite fracture properties: Method, validation, and applications. Journal of Applied Mechanics. 2016;83:071006.

[24] Jen YM, Chiou YC, Yu CL. Fracture mechanics study on the intermetallic compound cracks for the solder joints of electronic packages. Engineering Failure Analysis. 2011;18:797-810.

[25] Daud R, Ariffin AK, Abdullah S. Validation of crack interaction limit model for parallel edge cracks using two-dimensional finite element analysis. International Journal of Automotive and Mechanical Engineering. 2013;7:993-1004.

[26] Anderson TL. Fracture mechanics: Fundamentals and applications: CRC press; 2017.

[27] Bhate D, Subbarayan G, Nguyen L, Zhao J. Singularities at solder joint interfaces and their effects on fracture models: Part i. IEEE 11th Intersociety Conference on Thermal and Thermomechanical Phenomena in Electronic Systems, 2008. p. 73845. 